\title{
Resting stated-tractography-fMRI in initial phase of spiritual possession - A case report
}

\author{
José Luis Mosso Vázquez ${ }^{1 *}$, Carlos Jesús Castañeda González ${ }^{2}$, Brenda K. Wiederhold ${ }^{3}$, Fausto Nocedal ${ }^{4}$ and Eduardo Díaz Covarrubias $^{5}$ \\ ${ }^{1}$ Emergence Surgery Service, Regional Hospital number 25, Social Security Mexican Institute, México City \\ ${ }^{2}$ Pshychiatric Hospital, Fray Bernardino Álvarez, México City \\ ${ }^{3}$ The Virtual Reality Medical Center, San Diego, California, USA \\ ${ }^{4}$ Trauma and Orthopedic Hospital, Magdalena de las Salinas, Social Security Mexican Institute, México City \\ ${ }^{5}$ Catholic priest, archdiocese of México
}

\begin{abstract}
Objective: A cortical and subcortical area involved in a Functional Magnetic Resonance in a young woman in the first phase of a spiritual possession induced by an exorcism is presented.

Background: Female 29 years of age, university student, from dysfunctional family. She began her suffering 11 years ago with personality dissociation, characterized by aversion to sacred objects and images, and psychomotor agitation with transient states of loss of consciousness with manifestations of spiritual possession that required psychiatric, and psychological treatment, and 5 exorcisms without improvement over a period of ten years. She is currently taking and has taken, clonazepam for ten years. Laboratory studies, EEG, brain scans (Computed tomography CT-scan) and Functional Magnetic Resonance (fMRI) reveal no evidence of organic or functional diseases.

Methodology: The patient was initially evaluated by a psychologist, psychiatrist, neurosurgeon, and GI endoscopist, who excluded brain and gastrointestinal disorders, with complete medical record, blood tests, upper gastrointestinal endoscopy with biopsies and neuroimaging. With informed consent, a fMRI was accomplished before and in the beginning of a possession induced by exorcism performed by a Catholic priest.

Results: Cortex, midbrain, brain stem and cerebellum anatomy were normal on the brain scans and MRI. Tractography performed by diffusion tension imaging was determined before performing the exorcism and a resting state in the initial phase of possession because the patient progressively presented with psychomotor agitation. Tractography corresponding to the left brain of the corticospinal tract, uncinate fasciculum and superior longitudinal fasciculum was tangled out compared to the right hemispheres. The morphology of the corpus callosum was symmetrical. The resting state presented greater temporal and parietal lobe activity at the cortical level with subcortical areas with less activity such as the amygdala, the, basal ganglia, and the brain peduncle. The corpus callosum showed no activity other than the minor forceps or rostrum. Bradycardia and increased respiratory rate were the most important manifestation during possession. The neurovegetative response subsequent to gastric content vomiting occurred during the recovery state. 30 days after the exorcism, the patient had 3 spiritual possessions. The agent's (possessor) name is Estencaster.

Conclusions: $\mathrm{fMRI}$ is the most effective method to measure the cortical and subcortical activations areas involved in religious experience and patients possessed. The involved cortical and subcortical areas described make note that the temporal and parietal lobe are the brain lobes mainly involved in the present case of possession. However, due to the involuntary motor activity and the patient's loss of consciousness, it is not possible to perform the analysis completely in this case. The patient presented a generalized catatonic state at the beginning of the possession and psychomotor agitation of the head in a progressive way which permitted us to only perform the recording of Blood Oxygen Level Dependent (BOLD) for 6 minutes, thus allowing us to interpret part of the sensory-motor and verbal behavior and the low frontal response induced by the "possessor". Exorcism is an effective but invasive method to induce a possession state if other options or conditions are not available to provide patient safety, to protect against an increased neurovegetative response, where there is a risk of bronchospasm, aspiration, severe bradycardias, hypothermia, and even injuries induced by a possessor with greater aggressiveness. The use of Virtual Reality with images or sacred objects may prove a useful (and perhaps safer) for the induction of less aggressive agents. In agents such as the Demon, sedatives are an alternative for a corporal and behavioral control to perform a complete fMRI.
\end{abstract}

\section{Introduction}

This case is unique because there are not references in the scientific research or literature related with fMRI and spirit possession due to the clinical limitations to control a patient's agitations. There are theories and an approach between neurological signs and symptoms with neurological centers and pathways involved in spirit possessions. Many authors have published brain areas related with religious experiences only. Following we describe techniques to brain imaging studies.

Functional Magnetic Resonance Imaging (fMRI) is a specific magnetic resonance imaging method that measure brain activity by detecting associated changes in the blood flow (Trough low frequency BOLD signal in the brain). The results displayed in images are represented graphically by colors coding the strength of activation across the brain

^Correspondence to: José Luis Mosso Vázquez, Emergence Surgery Service, Regional Hospital number 25, Social Security Mexican Institute, México City, E-mail: quele01@yahoo.com

Key words: spiritual possession, exorcism, $f M R I$, resting state, devil

Received: April 20, 2018; Accepted: May 2, 2018; Published: May 7, 2018 
or the specific region studied. In this case the windows were open 6 minutes and 56 seconds Tractography (TG) [1-7]. Is a non-invasive technique that enables the fibers of the white substance of the subcortical pathways of the subcortical regions such as midbrain, cerebellum and brainstem. This technique can study the projection, association, and commissural tracts or fasciculus. TG is useful to demonstrate, tumors, ischemic and demyelinating diseases. The following pathways can be explored with this method. Associative pathways: Inferior fronto-occipital fasciculus, Uncinate fasciculus, upper frontooccipital fasciculus, Upper longitudinal fasciculus, arcuate fasciculus, inferior longitudinal fasciculus and Cingulum. Projection pathways: Corticospinal tract, Corticobulbar tract, Cortico Ponto spinal tract, Radiated corona, internal capsule, optical radiations, Medial lemnisc, Inferior spinocerebellar fasciculus, upper spinocerebellar fasciculus, pontocerebellar tracts. Commissural pathways: Corpus callosum, anterior commissure, posterior commissure, gray interthalamic commissure, Psalterium or David lira [8]. Resting state. Resting state fMRI (rsfMRI or R-fMRI) is a functional brain imaging technique to evaluate regional brain activations that occurs when patient is not performing a specific task. This resting brain activity is observed through changes in blood flow in the vessels of the brain which creates what is referred to as a blood oxygen-level dependent (BOLD) signal that can be measured by fMRI. In this case, rsfMRI can be used to demonstrate brain areas activation in a possessed female during exorcism [9-11]. Patrick McNamara [12-14], describes the followings concepts, Spiritual possession. It is the control of the senses of an individual and of his agency by a supernatural agent. Exorcism. It is a ritual by which the supernatural agent is eliminated, returned to hell or deposited to an identity within an object in order to release the consciousness of the possessed. The Catholic and Roman rite of exorcism was described by Jesus in the following order: Prayer, purification, order to leave the body, and sacrifice (It is mandatory to know the name of the agent to control him). Exorcist. Is a priest with moral reputation and knowledgeable of the sacred book with the authorization of a bishop to be the vehicle of the divine power by means of a ritual that includes Psalm 53 to super-naturalize and to be able to purify and to sacrifice the possessed offering it to Jehovah. McNamara describes a group of 51 possessed patients, 37 (73\%) which were women and $14(27 \%)$ which were men. Adults: 28 (55\%), Teenagers/young adults: 10 (20\%), Children: $6(12 \%)$, older adults: 3 (6\%), non-specific: 4 (7\%). Religious affiliations were followings. Catholics: 17 (33\%), Christians: 8 (16\%), Jews: $3(6 \%)$, Non-specific: 23 (45\%). Agent's characteristics were, Demon: 34 (73\%), spirits: 14 (27\%), others: 2 (4\%), non-specific: $1(2 \%)$. Gender's agents were male: 20 (39\%), woman: 2 (4\%) and non-specific: 29 (57\%). 27 of $51(66 \%)$ deliberately sought treatment, 22 of 51 (66\%) performed exorcism and 6 of 51 (33\%) had recurrence.

Possessed patient presents, habit changes, mental and physical changes and external phenomena as follows. Behavioral changes (habits). They become violent against humans and animals, have dietary changes, changes in the way of dressing, sudden weight loss, lack of hygiene, insulting, insolent, uninhibited, humiliating, nightmares or night terrors, changes in sleep patterns and automutiliation. Mental changes. Slight adversity to places or religious objects, reaction to a sentence, amnesia telekinesis, ability to heal, have the name of the spirit or demon, agent's names, aversion to holy places, images or objects, control of data and time: precognition and retro cognition, telepathy, clairvoyance, control of energy, spontaneous fire, control of matter, gravitational force control,, teleportation, reaction to holy water even if it is not known it is holy water a reaction to being inside a circle, passage of the entity from one mind to the another., control of biology (Life) as health. Body changes. Increased strength, modification of posture, voice changes, lack of blinking, body stiffness, difficulty moving, unusual gait, decrease in body temperature, unexplained fatigue, speaking in unknown, multiple voices, pupillary changes, body distortion, spontaneous marks or signs on the skin, and bodily reaction on contact with holy water. Environment changes. Perception of not being alone, violent attack by an outside force, shadows or non-defined silhouettes of people, sounds without cause, decrease in ambient temperature, objects that move by themselves, disappear and/or reappear, religious articles that disappear or are destroyed, strange lights, spontaneous winds with closed windows, levitation of objects, listening to words, cries, and babble without the presence of people, and spontaneous fire.

An approach of brain structures involved with religious experience, McNamara describes the following structures: temporal lobes, corpus callosum, basal ganglia, substance nigra in brainstem, cingulum, hippocampus and amygdala. Recently a new research has found brain areas related with particular functions in temporal lobes and close areas as inter parietal, frontal and temporal area where neurosurgeon Olaf Blanke from Switzerland has demonstrated out of body experience (OBE) and autoscopy [8] by electrical stimulation with subdural electrodes in a patient with constant current $0.5-5.0 \mathrm{~mA}, 2 \mathrm{~s}$, train duration was applied at $50 \mathrm{~Hz}$ in a bipolar manner through adjacent contacts in the left and right areas above indicated [15-21].

\section{Methodology}

Medical record. Mexican female 31 age with a story of domestic violence by her father who suffers from alcoholism. When she was child she experienced night terrors and at the age of 19 years she put burning branches into her throat sliding them to her upper gastrointestinal system after her boyfriend left her. She has mind and behavior disorders characterized by nightmares, aggressive behavior, aversion to holy images, places and objects, appeared catatonic, and has changes in sleep patterns also. She lost weight suddenly, and present precognition sometimes, spoke in an unusual tongue difficult to understand, changed her voice low and guttural, inhuman strength, and decrease of her body temperature during possession (family testimony). She consulted both psychology and psychiatry with normal blood tests, and brain scan, EEG and MRI. She has been treated with clonazepam for ten years ago which has decreased the frequency of possessions. Her family brought the patient back to a priest to perform 5 unsuccessful exorcisms with expulsion of the two demons. The Demon expelled was Alito (8 hours for each exorcism) and the demon that persists is Estencaster. Her family participated in several rituals outside of the Catholic Church with the objective to expel the demon. She had high aggressive behavior until getting hit to the first priest. Now, normal conventional MRI, EEG (with mild generalized subcortical and cortical dysfunction, no seizures elements are observed), GI Endoscopy with erosive gastritis with Helicobacter Pylori present, and normal blood test. Treated with $2 \mathrm{mg}$ a day of clonazepam for the past 5 years and psychological diagnosis of anxiety syndrome. Psychiatrist ruled out organic or functional mental illnesses and decided to perform a second exorcism under spirit possession while patient was in fMRI. To proceed with a second exorcism the following conditions and material were mandatory. Religious conditions and materials. Fasting, sexual abstention, rosary, holy water, exorcised water and oil, incense, all participants should be fervent believers, signed priest and expert in exorcism with great reputation, recognized a authorized by the local bishop, possessed without any disease, valued by medical experts, and dressing in a purple stole. Medical material. Stethoscope, thermometer, blood pressure cuff, pocket lamp, ophthalmoscope, reflex hammer, and 
an oximeter. The first exorcism was done in a Catholic church at 19 hours on January 12, 2017 to register all symptoms and signs and to evaluate possession. Spiritual possession symptoms and signs were: Mental changes. Aversion to prayers, holy places and images. In the possession state aggressive behavior, insulting, insolent against priest and relatives has been observed. Neurovegetative response is present as vomiting during and after possession. She speaks in a strange tongue mixing English and a no understandable language. She had one adult demon with a male name (Estencaster), loss of consciousness during possession and amnesia in the recovery. Body changes. Increased strength, modification of posture, eyes rolled back, body stiffness, difficulty moving unusual walking, creeps if a reptile, clonic and tonic movements, sometimes catatonic. Her body temperature shows a decrease, along with, unexplained fatigue. Her relatives describe her pupils as "shaped like a cat or reptile". She can also move her ears. Here body movements are tonic and clonic and sometimes just catatonic. Environment changes. Family testimony describe, perception of not being alone, shadows or non-defined silhouettes of people, sounds without cause, decrease in ambient temperature, objects that move by themselves, strange lights, listening to words. She had no reaction to holy water when the priest gave her a drink without knowing what about the water was. This is the reason the priest consider that this is a spirit, not a demon. Vital signs which were measured include heart rate, respiration rate, blood pressure, and temperature. Final diagnosis to perform the second exorcism under fMRI were made as follows: Anxiety diagnosis by psychologist, brain without organic diseases diagnosis was done by a neurosurgeon, psychology disorder diagnosis by Catholic priest and exorcist, and brain without mental diseases disorders was done by psychiatry who decided to perform exorcism. Supported by normal brain scanner anatomy, generalized low-voltage cortical dysfunction in electroencephalogram, normal blood test, and positive helicobacter pylori in antral biopsies by upper GI Endoscopy.

Second exorcism. With written consent, patient accepted medical evaluation with multidisciplinary equipment to rule out organic and functional diseases or brain disorders as: schizophrenia, paranoia dissociative disorders, temporal seizures, complex temporal seizures, brain tumors, parasites, bacteria, virus and fungus, trauma and other mental diseases groups. Assessments were done by psychologist, GI endoscopist, psychiatrist and neurosurgeon. Blood measures, radiographs, electroencephalogram, gastrointestinal endoscopy, brain scanner, resting state-fMRI and tractography were done with a 3.0 Tesla Echo speed excite III H.D. 2006 equipment in a private hospital in Mexico City. Two radiology technicians where in the equipment control, one psychologist was to perform MRI, tractography and resting state. Two physicians inside the room assisted patient to take vital signs, to observe symptoms and patient's signs, and fix the head, arms and legs to the bed with the technicians' support. One physician assisted priest to make exorcism. One video camera recorded the procedure outside the MRI Room. Another video was recording episodes of the procedure in the control room. No metal objects were allowed in the room with the scanner. The patient was and underwent fMRI lying down on the bed.

First phase (12:40-13:00). With patient awake and conscious her head and neck were gently secured to the bed. fMRI was done for 20 minutes. Second phase (13:00-13:56). Priest began the Roman Catholic ritual of exorcism, with prayers, and verbal commands to leave the spirit of the possessed. Female presented progressively changed behavior, lost being and consciousness as possessed beginning with autonomic or visceral response. 13:10 Resting state-fMRI was performed for 6 minutes and 56 seconds while patient was possessed and a priest performed an exorcism, the spirit speaking in strange tongue or language, and priest doing laying on of hands on the possessed at a distance of 1-2 meters away from her head. Third phase (13:56-14:20). Patient is awake with much hot and visceral response such as nausea. She doesn't remember anything related to her possession and exorcism. She vomits $(300 \mathrm{ml})$ after 14:30. Vital signs including heart rate, breathing rate, oxygen saturation and blood pressure were measured before and during exorcism by physician assistance (Table 1).

\section{Results}

Exorcism under fMRI (April 6, 2017). Resting State-TractographyfMRI was done with difficulty because of her movements. Cortex, midbrain, brain stem and cerebellum anatomy are normal in the scanner and MRI (16 sequences, 2 difficult to analyze). Tractography (3 sequences before exorcism) were performed before exorcism. 3 resting states were done, with just one available to analyze in the initial phase of possession because the patient progressively presented psychomotor agitation mainly in her head and neck. Schedule process we can appreciate in Table 1. Tractography corresponding to the left brain of the corticospinal tract, uncinate fasciculum and superior longitudinal fasciculum were frayed compared to the right brain. The morphology of the corpus callosum was symmetrical (Figures 1-3). Resting state presented greater temporal and parietal lobe activity at the cortical level with subcortical areas with less activity such as the amygdala, the,

Table 1. MRI, tractographies and resting state sequences

\begin{tabular}{|c|c|c|c|}
\hline $\begin{array}{c}\text { Number of } \\
\text { sequences }\end{array}$ & $\begin{array}{c}\text { Before } \\
\mathbf{1 2 : 4 8} \mathbf{a} 13: 00\end{array}$ & $\begin{array}{c}\text { Exorcism } \\
\mathbf{1 3 : 0 0} \mathbf{a} 13: 56\end{array}$ & $\begin{array}{c}\text { After } \\
\mathbf{1 3}: 57 \mathbf{a} 14: 20\end{array}$ \\
\hline & $\begin{array}{c}12: 49 \\
\text { MRI }\end{array}$ & $\begin{array}{c}13: 06 \\
(2 \text { sequences })\end{array}$ & $14: 17$ (2 sequences) \\
& $12: 55$ (3 sequences) & $13: 49(2$ sequences $)$ & \\
& & $13: 56(2$ sequences $)$ & \\
\hline 3 Tractographies & $12: 48$ (3 sequences) & & \\
\hline 1 Resting state & & $13: 10$ to $13: 16$ & \\
\hline
\end{tabular}

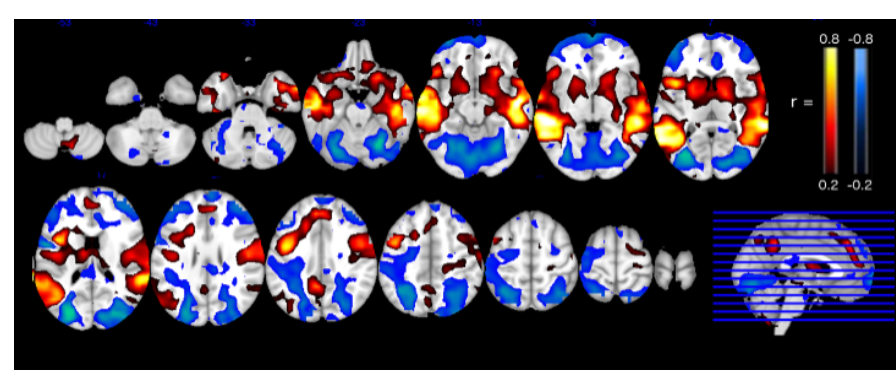

Figure 1. Images are from a BOLD fMRI (Resting state) showing yellows parts of the brain lighting up active areas of Temporal Parietal lobes. Medium brain activation in red color and less brain activation in blue

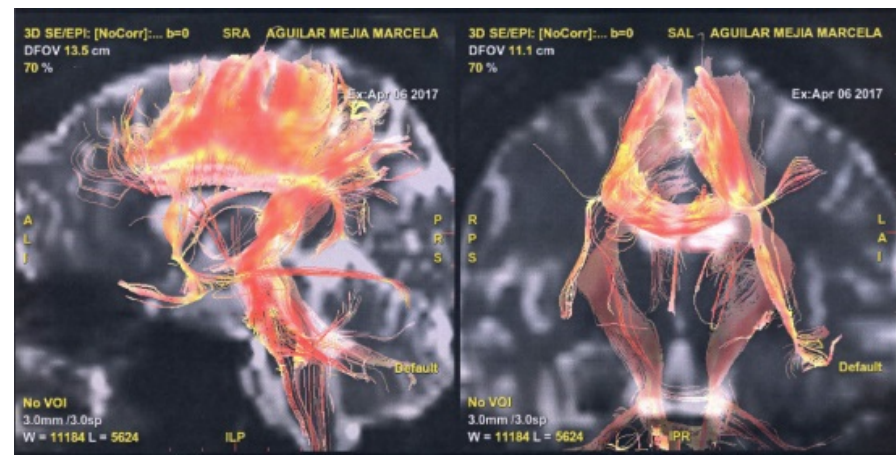

Figure 2. Corpus callosum and corticospinal tract (Tractography with tensor Diffusion imaging) 
basal ganglia, and the brain peduncle. The corpus callosum showed no activity save the minor forceps or rostrum (Figure 4).

Resting State-fMRI analysis. High brain activation is represented in yellow color (Table 2), medium activation in red (Table 3 ) and less activation in blue (Table 4) (Figure 4). This agent's behavior and fMRI anatomy relationship under possession and exorcism is, high (Yellow color) bi temporal activity characterized by eye, fascial and lips muscle's movements, high activity in oral expression (Broca's area activated), high primary auditory cortex activity also, primary somatosensory cortex activated and memory too. Medium activation in red color involve somatosensory cortex. Less activation represented in blue color involve cerebellum and important frontal or executive activity functions are reduced. Agent doesn't use visual cortex's areas much. DTITractography analysis. White matter pathways are integrated, where right to left pathway are represented in red color, up to down tracts in blue and front to posterior in green color. Just the left pathways are with a slight separation of fibers and these findings are not represented in behavior's agent or neurological manifestation. Corpus callosum doesn't have interhemispheric communication (Blue color). (See picture 2, 3 and 4). It means that the agent works in each hemisphere independently. Bradycardia and increased respiratory rate were the most important manifestation during possession. Cardiorespiratory response during exorcism, female presented bradycardia (42), hypotension, and high respiratory breathing (60 per minute) (Table 5). Neurogenerative response related to gastric content vomiting occurred in its recovery state. The agent's name is Estencaster an aggressive adult male that reject prayer and holy issues, speaks English and a rare tongue and take possession controlling the consciousness of the patient and motor brain areas with speech areas also. 30 days after the exorcism, the patient has 3 spirit possessions recurrences.

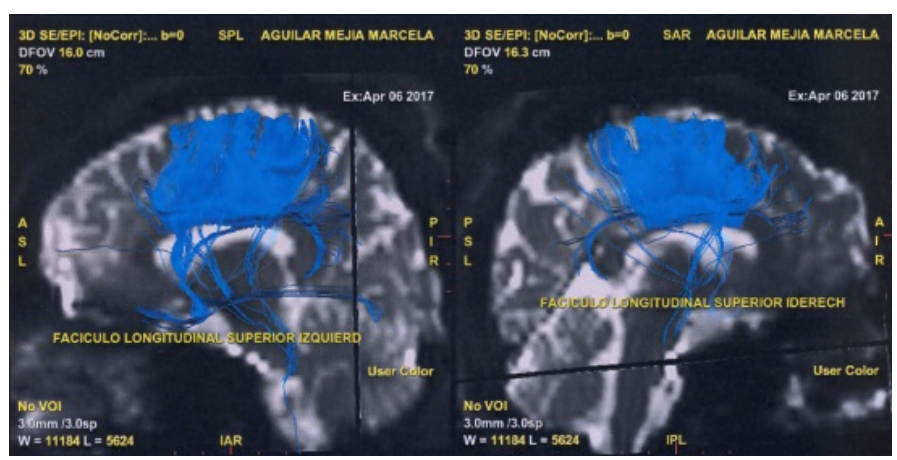

Figure 3. Left and right upper longitudinal fasciculus (Tractography with tensor Diffusion imaging)

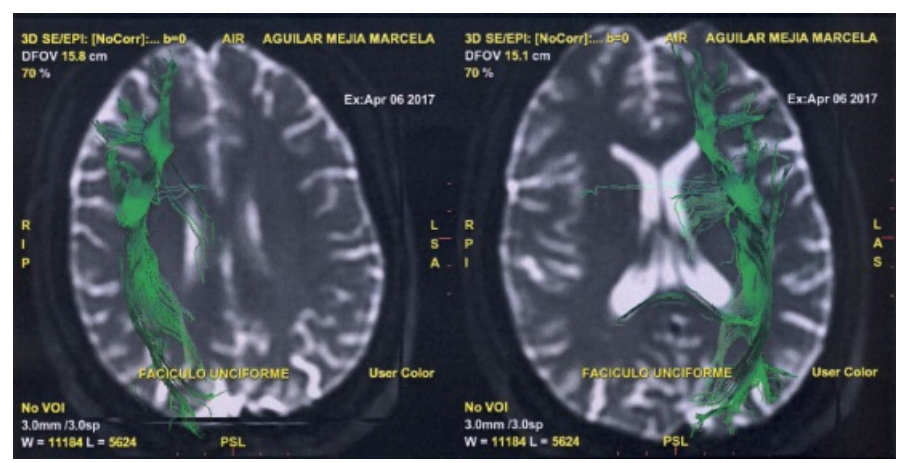

Figure 4. Right and left uncinate fasciculus. Coronal view (Tractography with tensor Diffusion imaging)

\section{Conclusions}

We present Resting State-fMRI and tractography with tensor Diffusion imaging. Findings in a possessed young female by an aggressive possessor. The more important background in her medical record is her violent father's presence and influence where he had participated in domestic violence against his wife since the patient was born. Her father's violence is associated with alcoholism and rapper as consequence more than 30 years. We also found a religious relationship in this case, twenty years ago the patients had been initiated into a secret order which he participated in for approximately a year and a half and swore loyalty and secrecy. In that same secret order, the patient was recognized as a member in her teens by means of a baptism. One year ago, the first Catholic priest made him renounce that institution by having him consent and his sign on a document that was burned along with all the material (clothing, books, uniform, certificates and medals) with him that participated. With the teachings of that order he left alcoholism when she was a kid. This experience unleashed night terrors when she was a child, and isolated and aggressive behavior when she was a teenager. Aggressive boyfriends as a father representation unleashed altered mental, behavioral and habit changes. Two supernatural possessors appeared for the first time when a boyfriend was aggressive with her. They appeared to have taking control of her mind, without organic, infectious, traumatic, degenerative or metabolic diseases. 5 exorcisms were made with a first Catholic priest, getting out just one agent (Alito). The second agent (Estencaster) persisted with the second Catholic priest that participates in our project. The importance of the RS-fMRI and DTI-Tractography with tensor diffusion imaging is to know the possessor's strategy to take control of the mind, and it became clear that the first step the possessor is to get into the consciousness of the possessed female represented in her frontal lobe (Specifically the area 10). Later or simultaneously the possessor controls all movements areas that involve cortex, midbrain brainstem and many areas of the cerebellum. At the same time, the possessor takes control of Broca's area to establish communication with the outside agency, information based or taken from the patient's memory areas is coming from temporal lobe. High activation areas indicate that the temporal lobe must be involved, and the frontal lobe must be inactive. The pathways to take control are motor somatosensory, auditory and visual pathways. It is so complex to establish where the possessor is, in a specific area of the brain. Curiously the hemispheres are not communicating they work independently. There is not technology to take the first instant when the agent appears. The technological limitation we found is the patient's movements that don't permit register any data making it impossible to perform fMRI. With this technology it is impossible to perform paradigms and explain where the brain's area is related with the supernatural agent's power that controls energy, matter, time (precognition, retro cognition), data, gravity and biology. This case is not demon (Lucifer, Beelzebub, Leviathan, etc.) agents with powers. We don't imagine how to hold the body of a possessed when they control energy, gravity, life, or matter. There is serious risk of injuries for the medical team and for patients. Patient's risks could be present because they can have broncho aspiration and wounds in a small space within the scanner equipment. Intravenous sedatives with the assistance of an anesthesiologist could be a solution for future works to control psychomotor agitation. In the patient's evolutions, she continues with the same symptom of spirit possession and the priest doesn't want to continuous participating with more exorcism. In addition, spirit possession is a regulatory system unleashed from family or social violence in this case. In a survey of 16 participants of this project, $100 \%$ have higher fear organized crime in Mexico than of a Demon. This project is the first approach of fMRI's 
Table 2. Yellow lighting up active of cortex lobes and Brodmann areas

\begin{tabular}{|c|c|c|}
\hline Brain Lobes & Right hemisphere Brodmann areas & Left hemisphere Brodmann areas \\
\hline Frontal & $\begin{array}{l}6 \text { Movement and control of proximal and trunk muscles of the body. } \\
8 \text { Control of eye movements } \\
44 \& 45 \text { Speech language production. Less involved. Boca's area. }\end{array}$ & $\begin{array}{l}43 \text { Primary gustatory cortex } \\
44 \& 45 \text { Speech language production. More involved. Broca's area. } \\
46 \text { Motor planning, organization and regulation }\end{array}$ \\
\hline Insula & 43 Primary gustatory cortex & \\
\hline Parietal & $\begin{array}{l}1,2 \text { Primary somatosensory cortex, main sensory receptive area for the } \\
\text { sense touch. }\end{array}$ & \\
\hline Temporal & $\begin{array}{l}20 \text { High level visual processing and recognition memory } \\
21 \text { Contemplate distance, recognition of known faces, and accessing word } \\
\text { meaning while reading. } \\
38 \text { Participate in language process, emotion, executive function and } \\
\text { memory. Not well defined. } \\
41 \& 42 \text { Primary auditory cortex. Basics of hearing, pitch and volume. }\end{array}$ & $\begin{array}{l}20 \text { High level visual processing and recognition memory } \\
21 \text { Contemplate distance, recognition of known faces, and accessing word } \\
\text { meaning while reading. } \\
38 \text { Participate in language process, emotion, executive function and } \\
\text { memory. Not well defined. } \\
41 \& 42 \text { Primary auditory cortex. Basics of hearing, pitch and volume. }\end{array}$ \\
\hline
\end{tabular}

Table 3. Red lighting medium active of cortex lobes, midbrain, brainstem, cerebellum and corpus callosum

\begin{tabular}{|c|c|c|}
\hline Subcortical areas & Right Brain & Left Brain \\
\hline Cortex & $\begin{array}{l}23 \text { Motor learning } \\
34 \text { Working memory } \\
\text { Uncus }\end{array}$ & $\begin{array}{c}6 \text { Movement and control of proximal and trunk muscles of } \\
\text { the body. } \\
8 \text { Control of eye movements } \\
25 \text { located in the cingulate region and implicated in the } \\
\text { normal processing of sadness } \\
34 \text { Working memory } \\
\text { Uncus }\end{array}$ \\
\hline Midbrain & $\begin{array}{l}\text { Amygdala } \\
\text { Globus pallidus }\end{array}$ & $\begin{array}{c}\text { Amygdala } \\
\text { Orbital gyrus } \\
\text { Subcallosal (Paraolfatory) area } \\
\text { Posterior limb of internal capsule } \\
\text { Globus pallidus }\end{array}$ \\
\hline Brain Stem & & $\begin{array}{l}\text { Temporopontines fibers } \\
\text { Cerebral peduncle }\end{array}$ \\
\hline Cerebellum & & Amygdala \\
\hline Corpus callosum & Forceps minor (rostrum) & \\
\hline
\end{tabular}

Table 4. Blue lighting less active of cortex lobes, midbrain, brainstem, cerebellum and corpus callosum

\begin{tabular}{|c|c|c|}
\hline Blue color & Right Brain & Left Brain \\
\hline Cortex & $\begin{array}{c}17 \text { Primary visual cortex (V1) } \\
18 \text { Secondary visual cortex (V2) } \\
\text { 19 Associative visual cortex (V3) } \\
\text { Prefrontal lobe } \\
\text { Anterior cingulum } \\
\text { Pre and postcentral semi oval substance }\end{array}$ & $\begin{array}{c}9 \text { Executive functions } \\
10 \text { Executive functions } \\
17 \text { Primary visual cortex (V1) } \\
18 \text { Secondary visual cortex (V2) } \\
\text { 19 Associative visual cortex (V3) } \\
\text { Frontal lobe } \\
\text { Anterior cingulum } \\
\text { Semioval substance } \\
\text { Posterior parietal area }\end{array}$ \\
\hline \multicolumn{3}{|l|}{ Midbrain } \\
\hline Brain Stem & $\begin{array}{l}\text { Corticovestibulars fibers } \\
\text { Corticonuclears fibers } \\
\text { Ponto cerebellum fibers }\end{array}$ & Ponto cerebellum fibers \\
\hline Cerebellum & $\begin{array}{c}\text { Anterior lobe (Quadrangular lobule), Superior vermis } \\
\text { (Central lobule, culmen, declive, folium), and inferior vermis } \\
\text { (Lingula). }\end{array}$ & $\begin{array}{l}\text { Left dented nucleus } \\
\text { Culmen }\end{array}$ \\
\hline Corpus callosum & Forceps minor (Esplenium) & Forceps minor (Esplenium) \\
\hline
\end{tabular}

Table 5. Vital signs before, during and after schedule exorcism

\begin{tabular}{|c|c|c|c|c|}
\hline Vital signs & $\begin{array}{c}\text { Before } \\
\text { (First phase) }\end{array}$ & $\begin{array}{c}\text { Exorcism 40 mins } \\
\text { (Second phase) }\end{array}$ & $\begin{array}{c}\text { After } \\
\text { (Third phase) }\end{array}$ \\
\hline Hour & $\mathbf{1 2 : 4 0}$ & $\mathbf{1 3 : 0 0 ~ 1 3 : 5 6}$ & $\mathbf{1 4 : 2 0}$ \\
\hline Heart rate & 52 & 4553 & \\
\hline Breathing rate & 18 & 45 & \\
\hline Temperature & 36.6 & 36.0 & \\
\hline Saturation & 96 & 9296 & \\
\hline Blood pressure & $99 / 62 \mathrm{mmHg}$ & $111 / 63$ & \\
\hline vomiting & 0 & $0300 \mathrm{ml}$ & \\
\hline & & 16 & \\
\hline
\end{tabular}

brain areas in spirit possession. Virtual Reality with images or sacred objects prove an alternative for the induction of less aggressive agents as well as to perform possession diagnosis. The proposal of this possessor is to bring about loss of consciousness, identity and the patient's will.
We agree with Sigmund Freud when he said that the origin or main factor of spirit possession is often guilt, low self-esteem and social transgression. The relevance of this project is the description of central nervous centers with imaging while a female is possessed. 


\section{Acknowledgement}

We thank Professor and Ex Colonel Richard M Satava for his important reviewing to improve the present article.

\section{References}

1. Deyoe EA, Bandettini P, Neitz J, Miller D (1994) Winans. Functional magnetic resonance imaging (fMRI) of the human brain. J Neurosci Methods 54: 171-187.

2. Pykett IL, Newhouse JH, Buonanno FS, Brady TJ, Goldman MR, et al. (1982) Principles of nuclear magnetic resonance imaging. Radiology 143: 157-168. [Crossref]

3. Recio Rodríguez M, Hernández Aceituno D, Hernández González LC, Martínez de V, Carrascoso FJ (2013) Imagen de tractografía 3T: anatomía y aplicaciones clínicas. Radiología e imágenes. Radiología 55: 57-68.

4. Biswal BB (2012) Resting state fMRI: a personal history. Neuroimage 62: 938-944. [Crossref]

5. van den Heuvel MP, Hulshoff Pol HE (2010) Exploring the brain network: A review on resting-state fMRI functional connectivity. Eur Neuropsychopharmacol 20: 519-534.

6. Rosazza C, Minati L (2011) Resting-state brain networks: literature review and clinical applications. Neurol Sci 32: 773-785.

7. Thiebaut de Schotten M, Ffytche DH, Bizzi A, Dell'Acqua F, Allin M, et al. (2011) Atlasing location, asymmetry and inter-subject variability of white matter tracts in the human brain with MR diffusion tractography. NeuroImage 54: 49-59. [Crossref]

8. Aranda R, Rivera M, Ramirez-Manzanares A (2014) A Flocking based method for Brain Tractography. Med Image Anal 18: 515-530. [Crossref]

9. Malachi Martin (1996) Hostage to the devil. The possession and exorcism of five contemporary Americans. Harper San Francisco; Reissue edition (October 1992).
10. Ferracuti S, Sacco R, Lazzari R (1996) Dissociative Trance Disorder: Clinical and Rorschach Findings in Ten Persons Reporting Demon Possession and Treated by Exorcism. J Pers Assess 66: 525-539.

11. Betty S (2005) The Growing Evidence for "Demonic Possession": What Should Psychiatry's Response be? Journal of Religion and Health 4: 1142-1149.

12. Patrick McNamara. Religion experience. Volume 2 (Rites to become possessed, Rites to exorcise "Demons"). 2011.

13. Patrick McNamara. Spirit Possession and Exorcism History, psychology, and neurobiology. Volume 2 (Rites to become possessed, Rites to exorcise "Demons". 2011

14. Patrick McNamara. Spirit Possession and Exorcism History, psychology, and neurobiology. Volume 2 (Rites to become possessed, Rites to exorcise "Demons". 2011.

15. De Ridder D, Van Laere K, Dupont P, Menovsky T, Van de Heyning P, et al. (2007) Visualizing out-of-body experience in the brain. NEngl J Med 357: 1829-1833. [Crossref]

16. Metzinger T (2005) Out of Body Experience as the origin of the concept of the soul. Mind \& Matter 3: 57-84

17. Blank O, Thut G (2006) Chapter 26, Inducing out of Body Experience, OBE, induced by neurological Disease, pp: 425-439

18. Blanke O, Ortigue S, Landis T, Seeck M (2002) Neuropsychology: Stimulating illusory own-body perceptions. Nature 419: 269-270.

19. Self-projection and the brain Randy L. Buckner1, 2, 3, 4 and Daniel C. Carroll1. Trends in Cognitive Sciences 2006.

20. Deeley Q, Oakley DA, Walsh A, Bell V, Mehta MA, et al. (2014) Modelling psychiatric and cultural possession phenomena with suggestion and fMRI. Elsevier. Cortex 53 : 107-119.

21. Buckner RL, Carroll DC (2007) Self-projection and the brain. Trends Cogn Sci 11 49-57. [Crossref]

Copyright: @2018 Vázquez JLM. This is an open-access article distributed under the terms of the Creative Commons Attribution License, which permits unrestricted use, distribution, and reproduction in any medium, provided the original author and source are credited. 